\title{
Development of a Semielliptical Partial Ground Plane Antenna for RFID and GSM-900
}

\author{
M. R. Zaman, ${ }^{1}$ R. Azim, ${ }^{1}$ N. Misran, ${ }^{1}$ M. F. Asillam, ${ }^{2}$ and T. Islam ${ }^{1}$ \\ ${ }^{1}$ Institute of Space Science (ANGKASA), Level 2, Faculty of Engineering and Built Environment Building, \\ Universiti Kebangsaan Malaysia, 43600 UKM Bangi, Selangor, Malaysia \\ ${ }^{2}$ National Space Agency of Malaysia, 62100 Putrajaya, Selangor, Malaysia
}

Correspondence should be addressed to M. R. Zaman; robelhk@yahoo.com

Received 24 October 2013; Accepted 11 November 2013; Published 9 April 2014

Academic Editor: J. S. Mandeep

Copyright (C) 2014 M. R. Zaman et al. This is an open access article distributed under the Creative Commons Attribution License, which permits unrestricted use, distribution, and reproduction in any medium, provided the original work is properly cited.

\begin{abstract}
A novel compact broadband patch antenna for UHF (ultrahigh frequency), RFID (radio frequency identification), and GSM-900 (global system for mobile communications) band is shown in this paper. The antenna is composed of an ellipse shape annular ring at the patch. The ground plane of the planar antenna is modified with a semiellipse shape slot. The structure can generate substantial amount of current at the feed-line. The geometry of the antenna is evaluated by using HFSS simulation software and deliberated across the paper. Parametric study is exhibited to delineate the response change of the antenna. The antenna has a physical width of $0.24 \lambda$ and length of $0.3 \lambda$. It covers a frequency starting from $0.9 \mathrm{GHz}$ to $1.08 \mathrm{GHz}$. A fractional bandwidth of $18.2 \%$ has been achieved from $0.9 \mathrm{GHz}$ till $1.08 \mathrm{GHz}$. An average gain of $5.5 \mathrm{dBi}$ is achieved at the resonance frequency. The simulated and measured results have good agreement.
\end{abstract}

\section{Introduction}

Microstrip antennas are becoming more popular in communication systems day by day. With the help of cost effective substrates and different copper shapes over and under the substrate, researchers are getting new bands of interest with comparatively less complexity than other types of antennae. Recent advances in radio communications have increased the demand in the antenna technology.

A RFID reader antenna using metamaterial is shown in [1]. Coupled branch-line is used to attain dual frequency performance. However, the measured $S_{21}$ response of the antenna falls below $-5 \mathrm{~dB}$ by introducing loss to the coupled line. A rectangular slot is introduced in the ground plane with a circular ring at the patch in [2] to enhance the impedance bandwidth. Another near field RFID reader antenna is exhibited in [3] to have a reading performance of about $7 \mathrm{~cm}$. Despite that, the antenna has a bulky dimension of $882 \mathrm{~mm} \times 80 \mathrm{~mm}$. A compact rectangular planar antenna is proposed in [4] with a small size and wideband performance. In [5], an antenna is presented for mobile RFID reader. Though the antenna evaluates quadrifilar spiral antenna
(QSA) technology for RFID application, nevertheless the antenna gain is as low as $0.06 \mathrm{dBic}$. An S-shaped impedance matching network is used in designing a mobile RFID reader for $2.45 \mathrm{GHz}$ in [6]. Although the antenna has a gain of $6 \mathrm{dBi}$ at the operating frequency, nonetheless, the antenna thickness is $11 \mathrm{~mm}$ which gives a drawback for portable applications. A RFID reader antenna with L-shaped ground plane is displayed in [7]. The antenna has a dimension of $250 \mathrm{~mm} \times 105.5 \mathrm{~mm}$ which is sizable in RFID application. Circular slot is introduced to have dual frequency response in $[8,9]$ by using FR4 substrate. This RFID reader antenna has a measured gain of $3.5 \mathrm{dBi}$ at the operating frequency. A half ellipse shape antenna is designed in [10] for vital sign detection at $400 \mathrm{MHz}$ frequency. In the paper the ellipse shape antenna is compared with a bowtie shape antenna. The impedance characteristics of the ellipse shape antenna jump over $150 \Omega$ at the claimed frequency with an imaginary value of $-j 20 \Omega$. Another half ellipse shape antenna with different height of backed cavity above ground is shown in [11]. The antenna shows an improvement over popular bowtie shape UWB antenna. However, the VSWR of the proposed antenna is greater than 2 at the claimed frequency. An ellipse-loaded 


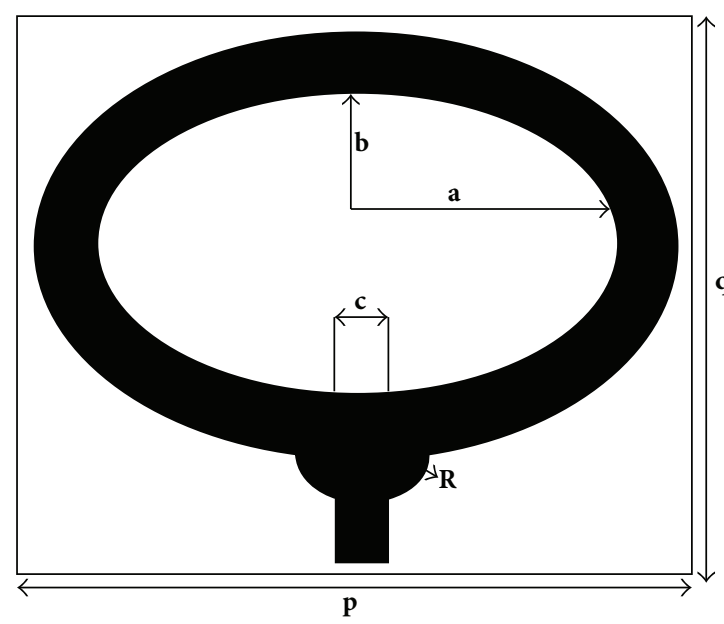

(a)

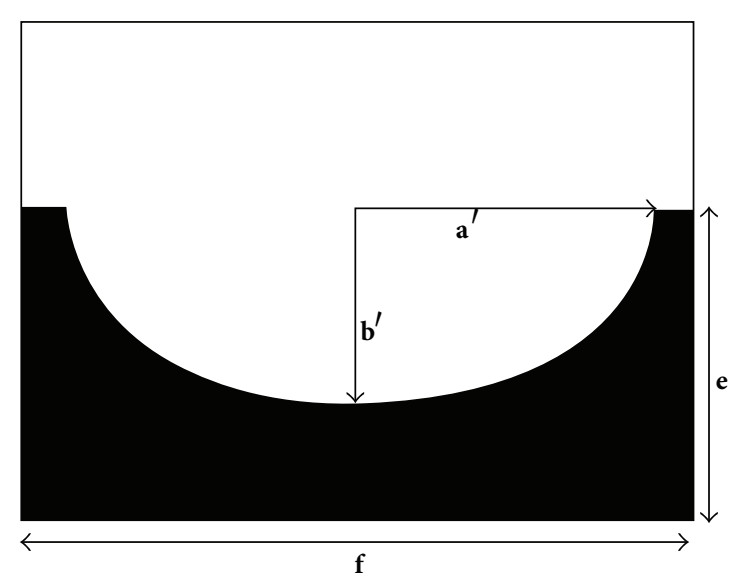

(b)

Figure 1: Proposed antenna dimensions (a) patch and (b) ground plane.

circular slot array for millimetre-wave WPAN applications is presented in [12]. Liquid crystal polymer (LCP) is used for the antenna design. In the design, a metallic reflector is used to make the radiation limited which makes the antenna size bulky and bigger in dimension. In [13] a design of elliptical microstrip patch antenna is presented using artificial neural networks to gain circular polarization. Nonetheless the antenna return loss at the target frequency is $-6.25 \mathrm{~dB}$ which is not acceptable in $-10 \mathrm{~dB}$ return loss scale. A theoretical and experimental investigation of an elliptical annular ring shape antenna is shown in [14]. The analysis is carried out using generalized transmission line model. A planar monopole antenna fed by an offset-microstrip line is shown in [15]. A circular ring is used to achieve the dimension. Another antenna is proclaimed in [16] with coplanar ground plane. The antenna is compact and one sided. Broadband and multiband antenna designs are shown in [17] using ellipses shape with the help of genetic algorithm to create amorphous shape. Nevertheless, the results presented do not include any result showing gain of the antenna. Curve fitting technique is shown in [18] for patch antenna using particle swarm optimization (PSO). A compact dual ellipses monopole antenna is printed in FR4 substrate [19]. No result on the gain of the antenna is demonstrated. In [20] an ellipse shape crescent slot broadband microstrip antenna is shown. Parametric studies are shown for different substrate thickness. However, the antenna results are simulated and not validated using fabricated antenna results. Different structure of the antenna is presented in finding different frequencies throughout the research of microstrip antenna design. FR4 substrate is being used widely for different applications of antenna nowadays due to its low price and durability. Ground plane modified wideband antenna is shown in [21] which uses FR4 substrate. From here it can be seen that FR4 substrate can be used to have wideband performance.

In this paper, an elliptical shape antenna is shown with modified ground plane. The antenna is designed for a frequency starting from $0.9 \mathrm{GHz}$ to $1.08 \mathrm{GHz}$. The proposed antenna is compact in size with a length, width, and height of $100 \mathrm{~mm}, 80 \mathrm{~mm}$, and $1.6 \mathrm{~mm}$, respectively. The measured results of the antenna are shown to have good agreement with the simulated result.

\section{Methodology}

The antenna is designed using FR4 substrate with dielectric constant of $\varepsilon_{r}=4.55$. The thickness of the FR4 substrate is $H=1.6 \mathrm{~mm}$. Figure 1 shows the proposed microstrip antenna design. The antenna patch is shaped as an ellipse with a major radius of $30 \mathrm{~mm}$ with a ratio of 1.5 with the minor radius of the ellipse. This is the outer border of the annular shaped ellipse. The inner part of the annular ellipse is cut using another ellipse with a major radius of 25 with a ratio of 1.4 with the minor radius. Both ellipses are centered at the origin so that the elliptic slot produced in the middle of the ellipse shaped patch has equal distance from all the sides of the antenna. A feed-line of width $c=8 \mathrm{~mm}$ is attached with the annular elliptical patch and extended to the edge of the FR4 PCB. The whole structure makes a " $\mathrm{T}$ " shaped junction. A semicircle is introduced at the " $T$ " shaped junction to match the impedance of the feed-line. First the semicircle is drawn which overlaps both the annular elliptical ring and the feed-line. Then all three structures are merged to have one basic structure. The semicircle overlaps the feed-line which is united with each other. A rectangular is drawn with a width and length of $45 \mathrm{~mm}$ and $100 \mathrm{~mm}$, respectively, at the ground plane. It is modified with the cutting edge of a semiellipse which has a major radius of $30 \mathrm{~mm}$ with 1.5 ratios with the minor radius.

The effective relative permittivity of the patch antenna can be calculated as

$$
\varepsilon_{e}=\frac{\varepsilon_{r}+1}{2}+\frac{\varepsilon_{r}-1}{2(\sqrt{(12 h / X)+1})} .
$$

Here, $H$ is the thickness of the substrate, $\varepsilon_{r}$ is FR4 relative permittivity, and $X$ is strip width. 


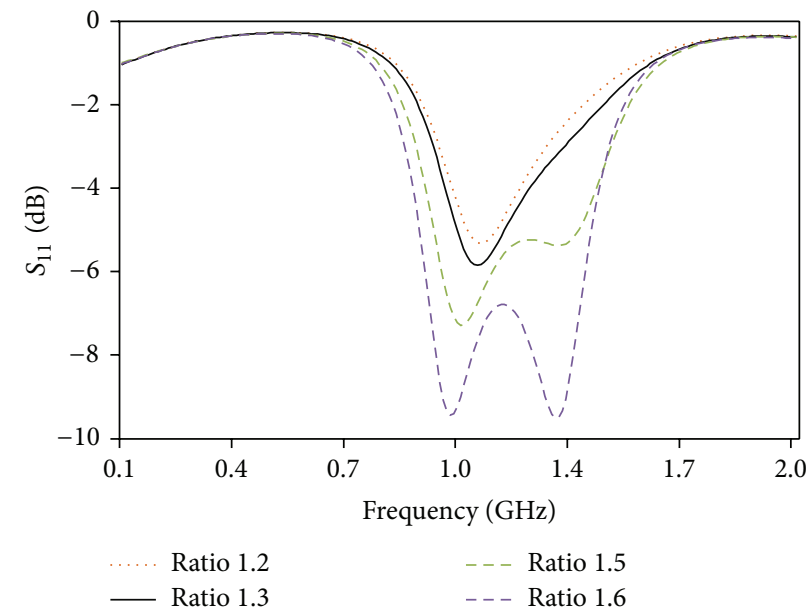

FIGURE 2: $S_{11}$ response for the change in radius ratio of the inner elliptical shape of the annular ring at patch.

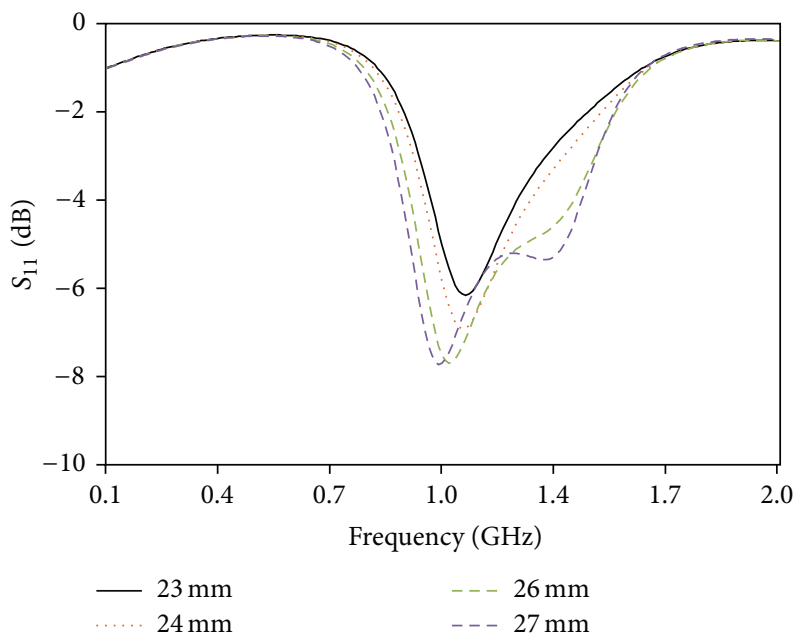

FIGURE 3: $S_{11}$ response for the change in major radius $($ ratio $=1.4)$ of the inner elliptical shape of the annular ring at patch.

For the annular ellipse shape patch the effective semiminor of the outer and inner axis is given by [22]

$$
\begin{array}{r}
b_{e 2}=b_{2}\left[1+\frac{2 d}{\varepsilon_{r} \pi b_{2}}\left\{\ln \left(\frac{b_{2}}{2 d}\right)+\left(1.41 \varepsilon_{r}+1.77\right)\right.\right. \\
\left.\left.+\frac{d}{b_{2}}\left(0.268 \varepsilon_{r}+1.65\right)\right\}\right]^{1 / 2} \\
b_{e 1}=b_{1}\left[1-\frac{2 d}{\varepsilon_{r} \pi b_{1}}\left\{\ln \left(\frac{b_{1}}{2 d}\right)+\left(1.41 \varepsilon_{r}+1.77\right)\right.\right. \\
\left.\left.+\frac{d}{b_{1}}\left(0.268 \varepsilon_{r}+1.65\right)\right\}\right]^{1 / 2} .
\end{array}
$$

\section{Parametric Studies}

In Figures 2 and 3, parametric studies are shown by changing the ratio and major radius of the inner ellipse, respectively. While changing the radius and ratio of the ellipse, there are some limitations. If the radius ratio is taken bigger than 1.6, the inner slot of the patch becomes bigger and narrows the side lines of the annular ellipse resulting in narrow current distribution. Again the ratios lower than 1.2 result in a very small circle in the middle of the patch. The results are shown in Figure 2 due to the changes in radius ratio. The resonance response tends to decrease with the increment in ratio. In Figure 3, the radius of the major axis is changed without changing the ratio $=1.4$. The radius is changed from $23 \mathrm{~mm}$ to $27 \mathrm{~mm}$ and the response is shown in Figure 3. With the increment in the major radius, the resonance response tends to narrow down centering at the frequency of $1 \mathrm{GHz}$. The major radius increment results in more narrowed microstrip line at the top of the annular elliptical ring, resulting in narrowed current distribution at the region.

\section{Results and Discussion}

Figure 4 shows the fabricated antenna in FR4 substrate. The proposed antenna is simulated using the electromagnetic 


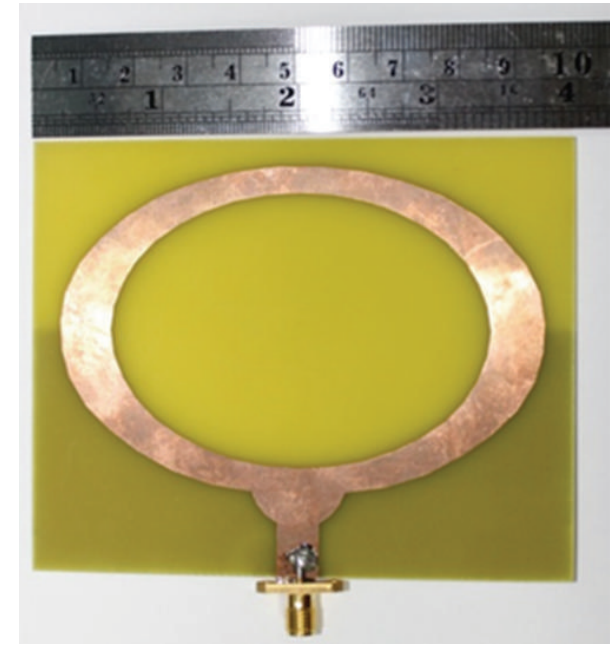

(a)

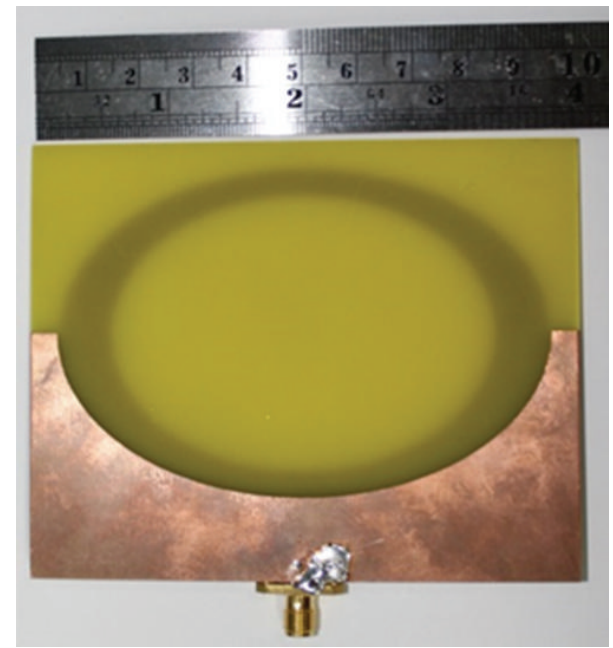

(b)

FIGURE 4: Prototype of the proposed antenna.

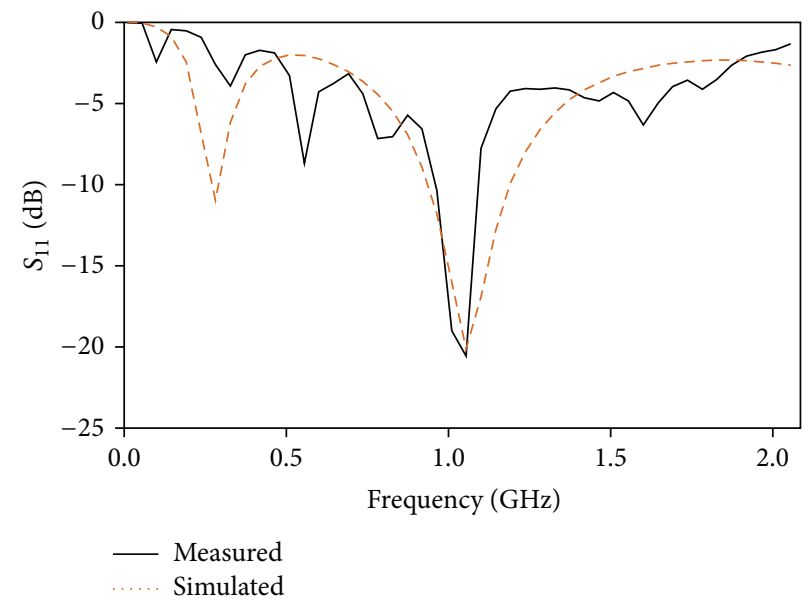

FIGURE 5: Measured $S_{11}$ response of the proposed antenna.

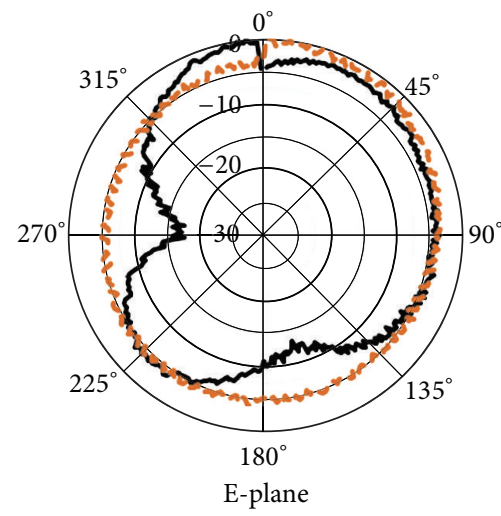

- Copolarization

- - Cross-polarization

(a)

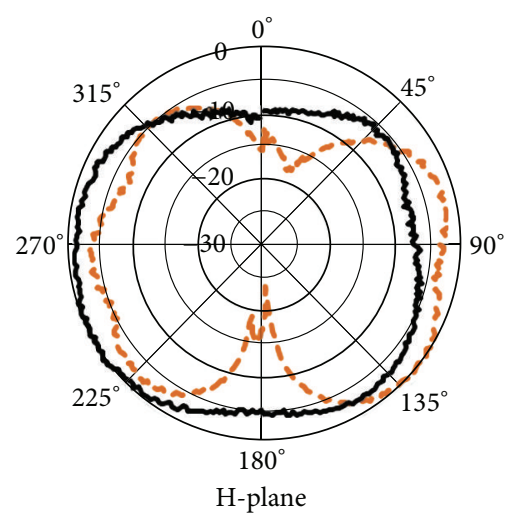

- Copolarization

- - Cross-polarization

(b)

FIGURE 6: Measured normalized radiation pattern of the proposed antenna. 


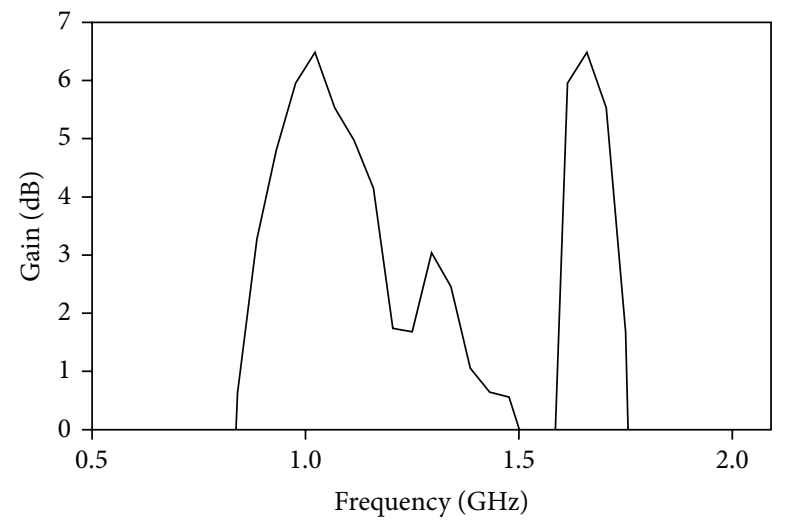

FIGURE 7: Measured gain of the proposed antenna.

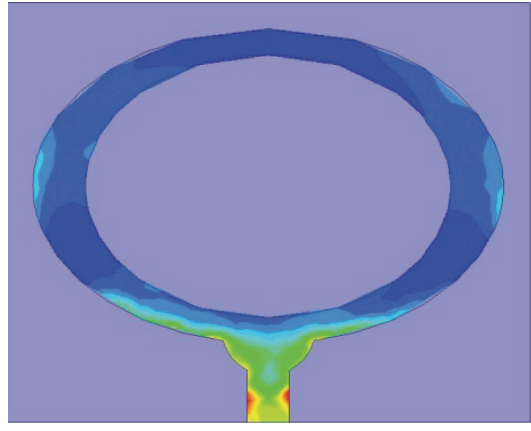

(a)

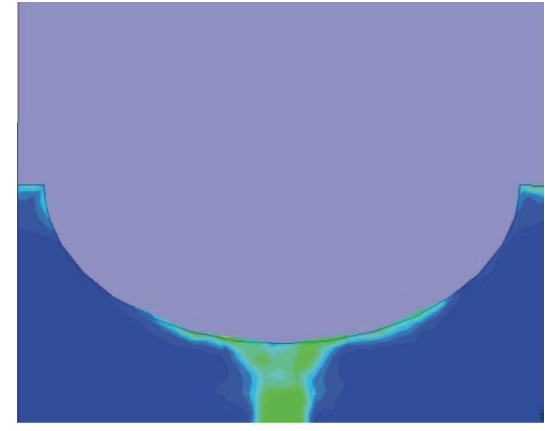

(b)

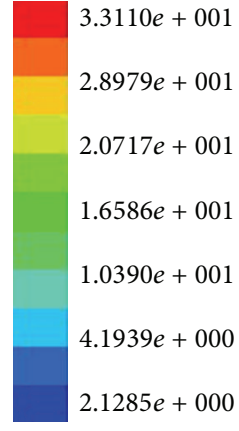

$2.1285 e+000$

FIGURE 8: Simulated current distribution of the (a) antenna patch and (b) ground plane.

TABLE 1: Design specification of the antenna.

\begin{tabular}{lc}
\hline Dimension & Value $(\mathrm{mm})$ \\
\hline Patch ellipse major radius, $a$ & 30 \\
Patch ellipse minor radius, $b$ & 20 \\
Ground ellipse major radius, $a^{\prime}$ & 30 \\
Ground ellipse minor radius, $b^{\prime}$ & 20 \\
Feed-line width, $c$ & 8 \\
Semicircle radius, $R$ & 9 \\
Ground plane width, $e$ & 45 \\
Ground plane length, $f$ & 100 \\
Antenna length, $p$ & 100 \\
Antenna width, $q$ & 80 \\
\hline
\end{tabular}

simulating software Ansoft HFSS. The software is based on finite element method (FEM). The antenna is measured using a power network analyser of model number E8358A. A horn antenna of model number SAS 571 is used to measure the radiation pattern and gain of the antenna. The antenna patch and ground are fed by a $50 \Omega$ SMA connector. The antenna width is $80 \mathrm{~mm}$ and length is $100 \mathrm{~mm}$. 18.2\% fractional bandwidth of the antenna is achieved in the measurement result. A $-10 \mathrm{~dB}$ return loss bandwidth of $180 \mathrm{MHz}$ is found at the UHF band with center frequency of $0.99 \mathrm{GHz}(0.9 \mathrm{GHz}$ to $1.08 \mathrm{GHz}$ ). The measured resonance response of the proposed antenna is shown in Figure 5 and compared with the simulated result. Two resonance responses almost overlap each other. Though there is a small resonance at $300 \mathrm{MHz}$ in the simulation result, the resonance cannot be seen in the measured result. Also due to environmental effect, the measured resonance response shows more oscillation than the simulated result. The radiation patterns at the E-plane and H-plane are shown in Figure 6. The co- and crosspolarization of the antenna show omnidirectional radiation pattern at $945 \mathrm{MHz}$ frequency. The measured gain of the antenna is shown in Figure 7. A peak gain of $6.5 \mathrm{dBi}$ is achieved at $1 \mathrm{GHz}$ resonance frequency. The average gain at the resonance band is $5.5 \mathrm{dBi}$. Figure 8 shows the simulated current distribution at the patch and ground plane of the antenna at $1 \mathrm{GHz}$. From the current distribution, it can be seen that, at $1 \mathrm{GHz}$, the feed-line at the patch is showing a dense current distribution with a peak at both edges. A coupling with the ground plane is made by the patch feed-line which can be seen in Figure 8(b). The coupling continues throughout the edge of the ground plane and outer boundary of the elliptical shape annular ring at the patch. The dimensions of the proposed antenna are tabulated in Table 1.

\section{Conclusion}

A novel elliptical shaped annular ring patched planar antenna is shown in this paper for RFID and GSM-900 applications. A semielliptical partial ground plane is introduced at the bottom of the proposed antenna. The antenna has a $-10 \mathrm{~dB}$ 
TABLE 2: Dimension and gain comparison between UHF RFID reader antennas.

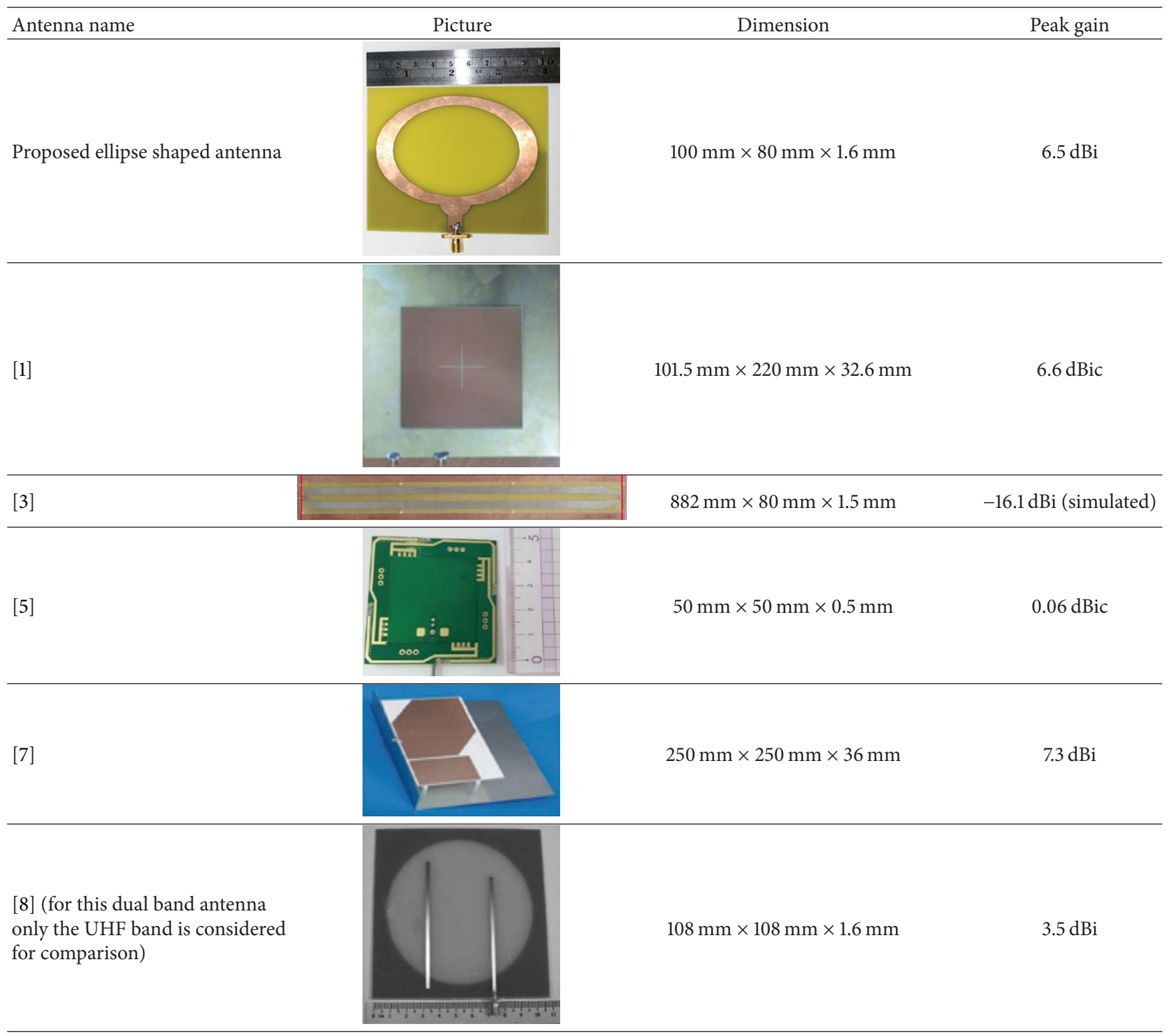

resonance response starting from $0.9 \mathrm{GHz}$ to $1.08 \mathrm{GHz}$ covering the band for UHF RFID and GSM-900 application (Table 2). The measured average gain is $5.5 \mathrm{dBi}$ with a peak gain of $6.5 \mathrm{dBi}$ at $1 \mathrm{GHz}$. The measured results agree with the simulated results. The antenna is compact in size and suitable for RFID and GSM-900 applications.

\section{Conflict of Interests}

The authors declare that there is no conflict of interests regarding the publication of this paper.

\section{Acknowledgment}

The authors would like to thank the Institute of Space Science (ANGKASA), UKM, for the assistance in every aspect while conducting this research.

\section{References}

[1] J. Youn-Kwon and B. Lee, "Dual-band circularly polarized microstrip RFID reader antenna using metamaterial branchline coupler," IEEE Transactions on Antennas and Propagation, vol. 60, no. 2, pp. 786-791, 2012.

[2] R. Azim, M. T. Islam, and N. Misran, "A planar monopole antenna for UWB applications," International Review of Electrical Engineering, vol. 5, no. 4, pp. 1848-1852, 2010.

[3] R. Ankang, W. Changying, G. Yao, and Y. Yong, "A robust UHF near-field RFID reader antenna," IEEE Transactions on Antennas and Propagation, vol. 60, no. 4, pp. 1690-1697, 2012.

[4] R. Azim, M. T. Islam, and N. Misran, "Printed planar antenna for wideband applications," Journal of Infrared, Millimeter, and Terahertz Waves, vol. 31, no. 8, pp. 969-978, 2010.

[5] L. Soo-Ji, L. Dong-Jin, J. Hyeong-Seok, T. Hyun-Sung, and Y. Jong-Won, "Planar square quadrifilar spiral antenna for mobile 
RFID reader," in Proceedings of the 42nd European Microwave Conference (EuMC '12), pp. 944-947, 2012.

[6] W. Tingqiang, S. Hua, G. Liyun, C. Huizhu, H. Jingyao, and Z. Huaiwu, "A compact and broadband microstrip stacked patch antenna with circular polarization for $2.45-\mathrm{GHz}$ mobile RFID reader," IEEE Antennas and Wireless Propagation Letters, vol. 12, pp. 623-626, 2013.

[7] Y. Pan, L. Zheng, H. J. Liu, J. Y. Wang, and R. L. Li, "Directly-fed single-layer wideband RFID reader antenna," Electronics Letters, vol. 48, pp. 607-608, 2012.

[8] J. J. Tiang, M. T. Islam, N. Misran, and J. S. Mandeep, "Circular microstrip slot antenna for dual-frequency RFID application," Progress in Electromagnetics Research, vol. 120, pp. 499-512, 2011.

[9] J. J. Tiang, M. T. Islam, N. Misran, and J. S. Mandeep, "Slot loaded circular microstrip antenna with meandered slits," Journal of Electromagnetic Waves and Applications, vol. 25, no. 13, pp. 1851-1862, 2011.

[10] J. J. Shao, C. Chen, J. Chen, Y. C. Ji, G. Y. Fang, and H. J. Yin, "Study of UWB half-ellipse antenna with a shallow backed cavity in vital sign detection," in Proceedings of the 14th International Conference on Ground Penetrating Radar (GPR '12), pp. 89-92, 2012.

[11] B. Wu, Y. Ji, and G. Fang, "Analysis of GPR UWB half-ellipse antennas with different heights of backed cavity above ground," IEEE Antennas and Wireless Propagation Letters, vol. 9, pp. 130133, 2010.

[12] A. R. Weily and Y. J. Guo, "Circularly polarized ellipse-loaded circular slot array for millimeter-wave WPAN applications," IEEE Transactions on Antennas and Propagation, vol. 57, no. 10, pp. 2862-2870, 2009.

[13] A. Agrawal, D. Vakula, and N. V. S. N. Sarma, "Design of elliptical microstrip patch antenna using ANN," in Proceedings of the Progress in Electromagnetics Research Symposium (PIERS '11), pp. 264-268, September 2011.

[14] A. K. Bhattacharyya and L. Shafai, "Theoretical and experimental investigation of the elliptical annular ring antenna," IEEE Transactions on Antennas and Propagation, vol. 36, no. 11, pp. 1526-1530, 1988.

[15] L. Liu, S. W. Cheung, R. Azim, and M. T. Islam, "A compact circular-ring antenna for ultra-wideband applications," Microwave and Optical Technology Letters, vol. 53, no. 10, pp. 2283-2288, 2011.

[16] A. T. Mobashsher, M. T. Islam, and N. Misran, "Wideband compact antenna with partially radiating coplanar ground plane," Applied Computational Electromagnetics Society Newsletter, vol. 26, no. 1, pp. 73-81, 2011.

[17] L. A. Griffiths, C. Furse, and Y. C. Chung, "Broadband and multiband antenna design using the genetic algorithm to create amorphous shapes using ellipses," IEEE Transactions on Antennas and Propagation, vol. 54, no. 10, pp. 2776-2782, 2006.

[18] M. T. Islam, M. Moniruzzaman, N. Misran, and M. N. Shakib, "Curve fitting based particle swarm optimization for uwb patch Antenna," Journal of Electromagnetic Waves and Applications, vol. 23, no. 17-18, pp. 2421-2432, 2009.

[19] Y. Xia, Z. Duan, and D. Edwards, "Compact printed dual ellipses monopole antenna for UWB system," in Proceedings of the 4th International Conference on Wireless Communications, Networking and Mobile Computing (WiCOM '08), pp. 1-3, October 2008.

[20] M. M. Sharma, V. Agrawal, S. Kumawat, N. C. Bajia, S. Gupta, and R. P. Yadav, "Ellipse shape crescent slot compact broadband microstrip antenna," in Proceedings of the International Conference of Recent Advances in Microwave Theory and Applications (MICROWAVE '08), pp. 868-870, November 2008.

[21] R. Azim, M. T. Islam, N. Misran, S. W. Cheung, and Y. Yamada, "Planar UWB antenna with multi-slotted ground plane," Microwave and Optical Technology Letters, vol. 53, no. 5, pp. 966-968, 2011.

[22] F. Alhargan and S. Judah, "Mode charts for confocal annular elliptic resonators," IEE Proceedings. Microwaves, Antennas and Propagation, vol. 143, no. 4, pp. 358-360, 1996. 

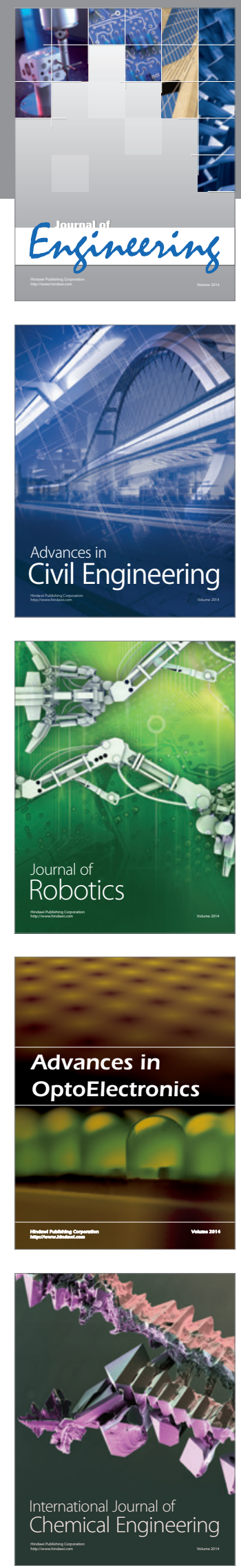

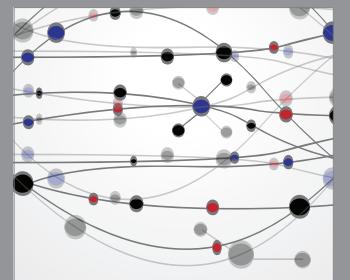

The Scientific World Journal
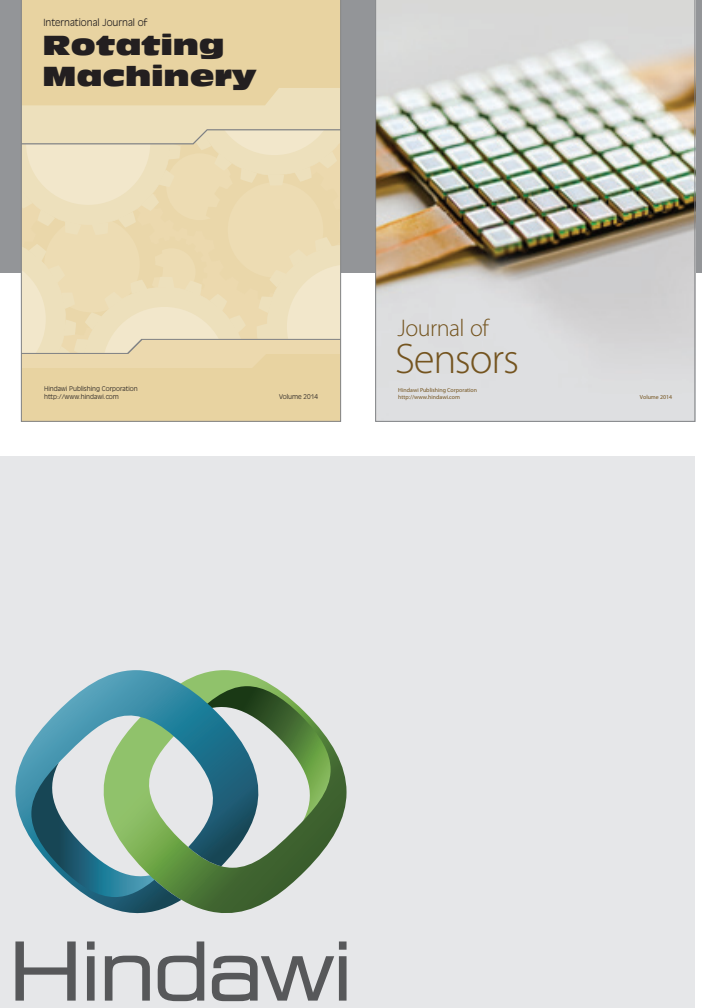

Submit your manuscripts at http://www.hindawi.com
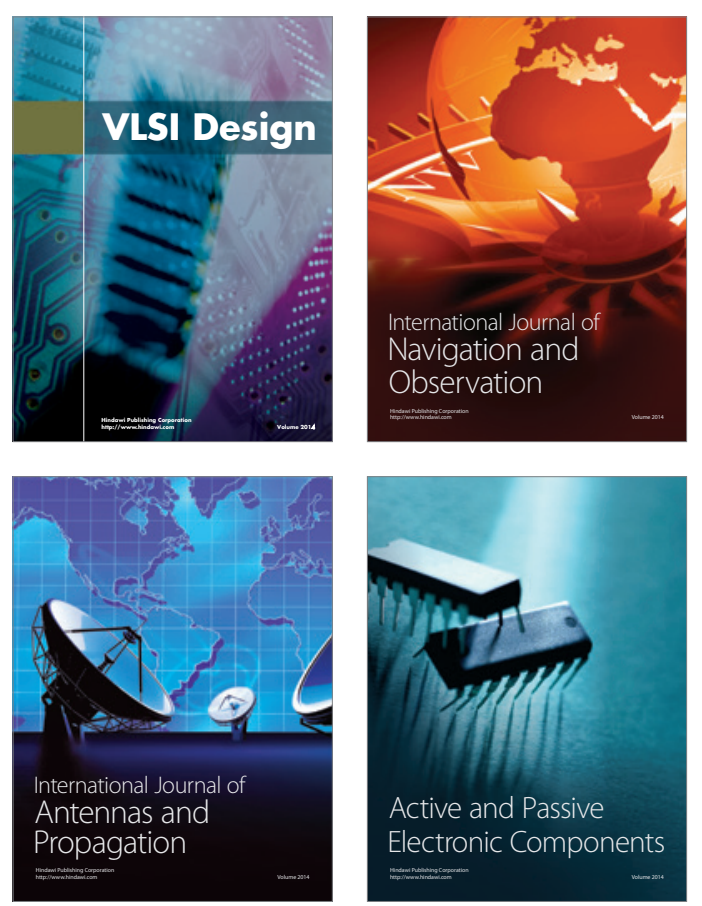
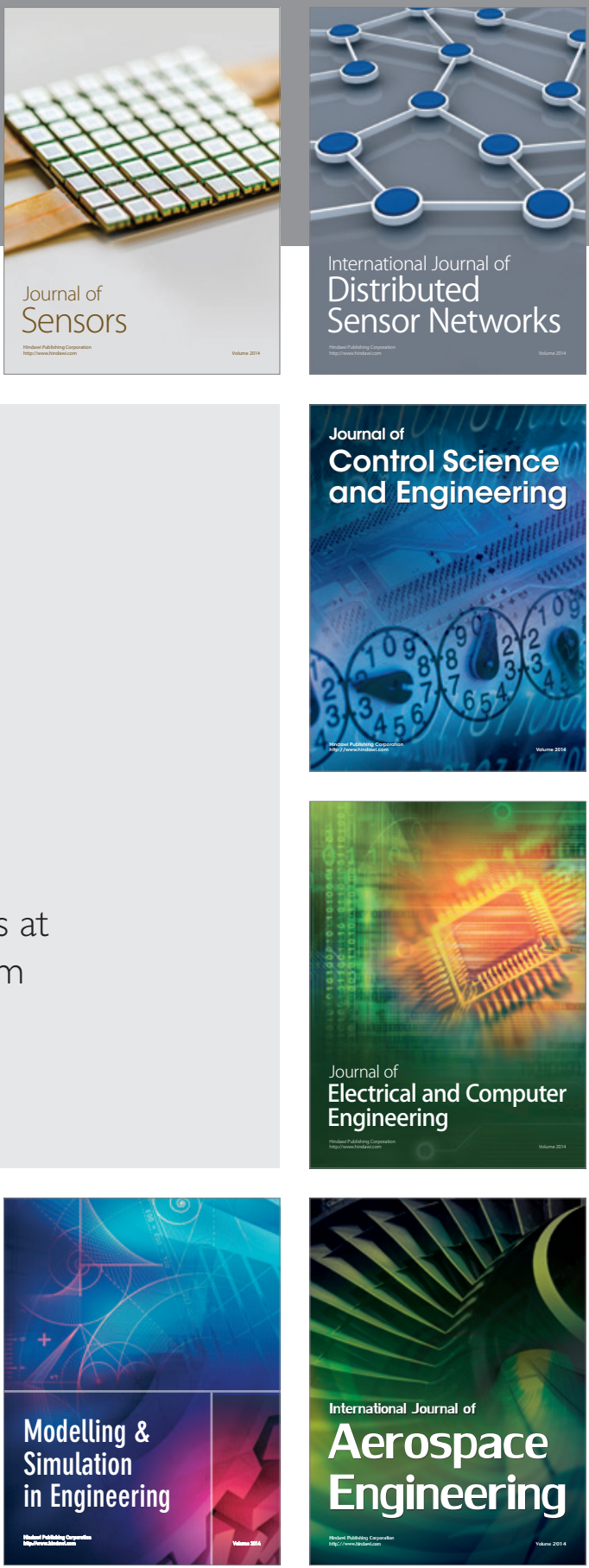

Journal of

Control Science

and Engineering
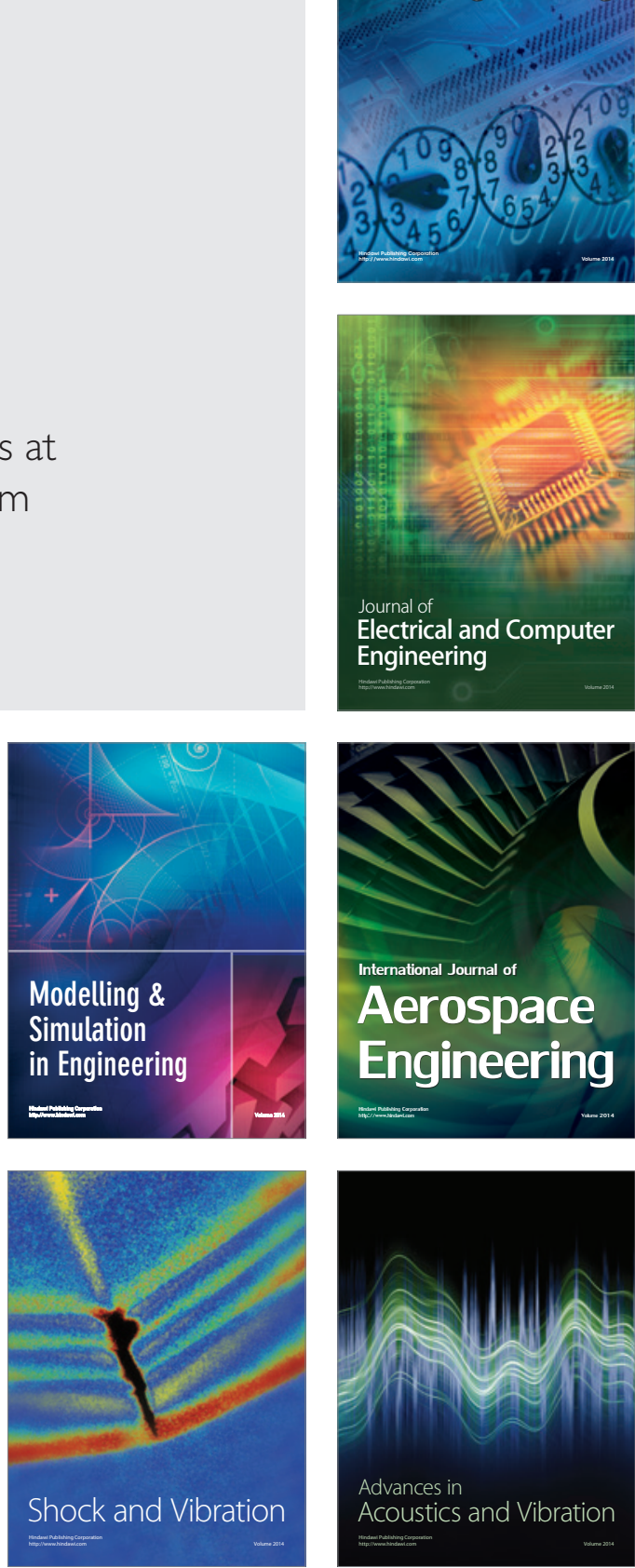